\title{
APLICAÇÃO DO SISTEMA DE GESTÃO AMBIENTAL NA MINIMIZAÇÃO DOS IMPACTOS AMBIENTAIS GERADOS POR UMA AGROINDÚSTRIA ABATEDORA DE AVES
}

\section{APPLICATION OF THE ENVIRONMENTAL MANAGEMENT SYSTEM IN MINIMIZING THE ENVIRONMENTAL IMPACTS GENERATED BY A POULTRY SLAUGHTER AGROINDUSTRY}

\author{
A. B. VANIN ${ }^{1 *}$; G. MARQUEZ ${ }^{1}$
}

${ }^{1}$ Universiade do Oeste de Santa Catarina, Joaçaba, SC, 89600-000, Brasil

*Universiade do Oeste de Santa Catarina, Joaçaba, SC, 89600-000, Brasil, Phone: +554935512014.

E-mail: adriana.vanin@unoesc.edu.br(A.B.VANIN)

Environmental impacts

A R T I C L E I N F O

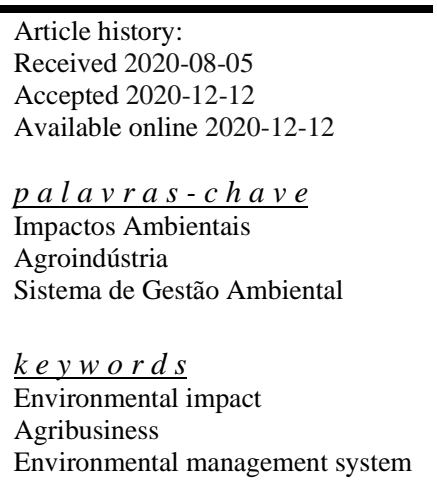

Environmental management system

\begin{abstract}
A B S T R A C T
The environmental management system is an important tool in the control and minimization of environmental impacts resulting from anthropic actions. The industrialization of poultry in southern Brazil is responsible for the generation of large volumes of liquid waste and the accumulation of solid waste, increasing the occurrence of negative environmental impacts. This study aimed to apply the Environmental Management System (SGA) in the assessment and minimization of environmental impacts generated by a chicken slaughtering agroindustry located in the west of Santa Catarina. Data collection enabled a diagnosis of the situation of the agribusiness at the beginning of the research, considering the impacts on the physical, biological and socioeconomic environment of the areas of direct and indirect influence and the characterization of the local vegetation cover. The system proved to be a technically viable tool, prioritizing the main environmental problems present, analyzing the entire production process of the agribusiness and identifying all points that should be improved to reduce environmental impacts, including liquid and solid waste.
\end{abstract}

R E S U M O

O sistema de gerenciamento ambiental é uma importante ferramenta no controle $e$ minimização dos impactos ambientais decorrentes de ações antrópicas. A industrialização de aves no sul do Brasil é responsável pela geração de grandes volumes de resíduos líquidos e acúmulo de resíduos sólidos, potencializando a ocorrência de impactos ambientais negativos. Este estudo teve como objetivo aplicar o Sistema de gestão ambiental (SGA) na avaliação e minimização dos impactos ambientais gerados por uma agroindústria de abate de frangos localizada no meio oeste de Santa Catarina. A coleta de dados possibilitou um diagnóstico da situação da agroindústria no início da pesquisa, considerando os impactos ao meio físico, biológico e socioeconômico das áreas de influência direta e indireta e a caracterização da cobertura vegetal local. O sistema mostrou ser uma ferramenta tecnicamente viável, priorizando os principais problemas ambientais presentes, analisando todo o processo de produção da agroindústria e identificando todos os pontos que deveriam ser melhorados para reduzir os impactos ambientais, abrangendo os resíduos líquidos e sólidos. 


\section{INTRODUÇ̃̃̃O}

A agroindústria, de modo geral, é uma organização que realiza a transformação de uma matéria prima derivada da agricultura, pecuária, aquicultura ou silvicultura. Para complementar o conceito inicial, Rodrigues et al. (2012) afirma que agroindústria "são unidades empresariais onde se realizam as etapas de beneficiamento, processamento e transformação de produtos agropecuários in natura até a embalagem, prontos para o consumidor".

Atualmente, a participação das agroindústrias no Produto Interno Bruto (PIB) situa-se em 5,9\%. (EMBRAPA, 2018). As agroindústrias de Santa Catarina, focam principalmente na produção de proteína animal (criação de suínos e aves) apresentam uma representatividade importante a nível de Brasil (PEREIRA, 2017) alcançando $1,5 \%$ do PIB e gerando aproximadamente 3,5 milhões de empregos diretos e indiretos. Neste sentido, as regiões sul e sudeste do país se destacam pela industrialização de aves que é mantida pelo elevado consumo dos mercados interno (70\% da produção) e externo $(30 \%)$ direcionados para mais de 150 países. (ABPA, 2016).

Um ponto importante a ser abordado refere-se aos impactos ambientais ocasionados por atividades agroindustriais e maximizados pela ausência de um sistema de gerenciamento ambiental adequado por parte da organização, que resulta em um equivocado direcionamento de resíduos líquidos e sólidos, potencializando a ocorrência de impactos ambientais negativos. (RAUPP; SELIG; SORIANO-SIERRA, 2015).

Diante disso, insere-se o Sistema de Gestão Ambiental (SGA), ferramenta que objetiva avaliar e controlar todos os possíveis impactos ambientais gerados por atividades industriais por meio da aplicação prática de uma política ambiental com foco no processo de melhoria contínua, proporcionado uma redução de impactos ambientais negativos. (MOURA, 2011).

Desta forma, o objetivo da pesquisa é aplicar o SGA na avaliação e minimização dos impactos ambientais gerados por uma agroindústria de abate de frangos localizada no meio oeste de Santa Catarina.

\section{REFERENCIAL}

\subsection{Sistema de Gestão Ambiental (SGA)}

Fogliatti et al. (2008) definem o SGA como uma estrutura organizacional que possibilita a avaliação e o controle dos impactos ambientais efetuados e complementam que a revisão e a otimização do SGA devem ser aplicadas continuamente para um adequado gerenciamento das atividades da organização.

O SGA é uma ferramenta utilizada pelas organizações para correção e prevenção dos impactos ambientais, a sua aplicação requer um levantamento do aspecto ambiental e do processo. A definição do aspecto ambiental, relaciona-se as atividades, produtos e ou serviços que podem interagir com o meio ambiente. Além disso, a identificação dos aspectos e impactos ambientais é a parte fundamental para o planejamento do SGA aplicado pelo método PDCA (Planejar, Fazer, Checar e Atuar) que é um sistema de melhoria contínua dos processos, também formado por partes agregadas e interdependentes. (BARAUNA et al., 2011).
Moura (2011) corrobora explicando que o SGA é aplicado com base no Ciclo PDCA e que ambos são métodos ou estruturas utilizadas para controlar, identificar impactos ambientais e um processo de melhoria contínua. A aplicação do SGA consiste na elaboração de responsabilidades para subsidiar uma Política Ambiental, onde encontram-se apresentados os meios a serem utilizados pela organização com o intuito de atingir e manter-se nas normas estabelecidas.

Dias (2017) detalha que o SGA é o conjunto de responsabilidades organizacionais, procedimentos, processos e meios que se adotam para a implantação de uma política ambiental e que, além disso, a gestão ambiental permite analisar a capacidade de carga de um sistema produtivo onde a organização está inserida e com isso, subsidiar a implantação meios de controle. A implantação adequada de um SGA contribui com o desenvolvimento sustentável da empresa.

A definição de sustentabilidade está associada a maneira com que são utilizados os recursos do meio ambiente preocupando-se não somente com as necessidades da geração atual, mas também, com as necessidades das gerações futuras. (BOFF, 2017).

Sabendo que as organizações são responsáveis por grande parcela dos impactos ambientais identificados, principalmente pela geração de resíduos originados nas atividades internas, estas passaram a adotar medidas para reduzir os impactos ambientais, pela aplicação de uma política ambiental incorporada pelas partes administrativa e de gestão ambiental da organização sob orientação dos órgãos ambientais. (LHAMBY; SENNA; CANES, 2010).

\subsection{Legislação Pertinente}

No que diz respeito às legislações a serem seguidas, no estado de Santa Catarina, a agroindústria deve possuir uma autorização ambiental emitida pelo Instituto do Meio Ambiente (IMA) de acordo com a Lei no 14.675, de 13 de abril de 2009. (SANTA CATARINA, 2009).

A Resolução do Conselho Nacional do Meio Ambiente Resolução ${ }^{\circ}$ 430, de 13 de maio de 2011 (CONAMA 430/11) é uma resolução relativo à gestão do lançamento em corpos de água receptora, referente aos efluentes, essa gestão corresponde as condições, padrões, parâmetros e diretrizes desse lançamento. (BRASIL, 2011). Os efluentes emitidos são originários de resíduos sólidos e destinados ao lançamento em corpos receptores, estando de acordo com Lei ${ }^{\circ}$ 14.675/2009, que visa a melhoria na qualidade ambiental e na proteção. (SANTA CATARINA, 2009).

A Lei $n^{\circ}$ 6.938/81, estabelece a Política Nacional do Meio Ambiente, tendo como principais objetivos, a preservação, recuperação e melhoria da qualidade do meio ambiente, ou seja, controla e efetua o zoneamento de atividades que são potencialmente poluidoras. Além disso, a NBR 10004 efetua a classificação dos tipos de resíduos de acordo com potencial poluidor ao meio ambiente e a saúde pública, assim, proporciona um gerenciamento adequado. (RIBEIRO; MORELLI, 2009).

De acordo com Ribeiro e Morelli (2009), a NBR 10004 classifica os resíduos em cinco grupos, sendo:

Classe A: resíduos potencialmente infectantes;

Classe B: resíduos químicos; 
Classe C: rejeitos radioativos;

Classe D: resíduos comuns;

Classe E: resíduos perfurocortantes.

\section{PROCEDIMENTOS METODOLÓGICOS}

A pesquisa foi desenvolvida em uma agroindústria localizada no meio oeste de catarinense. Na empresa ocorre todo o processo, deste a criação e engorda, até o abate dos frangos.

O estudo foi desenvolvido seguindo as etapas do ciclo PDCA (Figura 1). Iniciando pelo passo de planejamento, onde realizou-se o diagnóstico da agroindústria no que diz respeito a legislação pertinente e a produção de resíduos. A partir deste diagnóstico, traçou-se os objetivos e metas, e para isso, elaborou-se um plano acompanhado de estratégias para solucionar os problemas identificados na agroindústria relacionados aos impactos ambientais.

\section{Figura 1 - Ciclo PDCA}

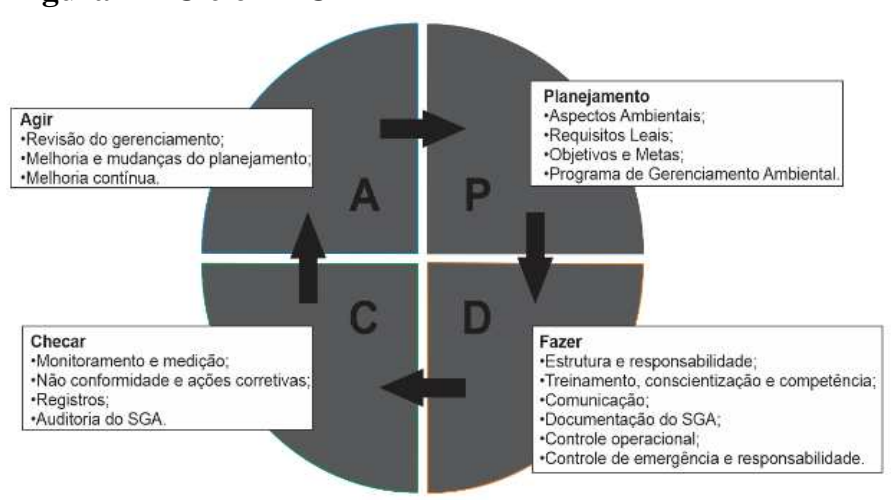

Fonte: Alves (2015)

O segundo passo referiu-se ao Fazer, no qual o planejamento elaborado foi então executado. A execução foi um treinamento dos colaboradores envolvidos no processo.

Finalizando a etapa do Fazer, iniciou-se o terceiro passo, Checar, avaliando o desempenho das melhorias propostas na etapa do planejamento, por meio da comparação entre o diagnóstico inicial e após a implantação do programa. A última etapa, Agir, que consistiu na revisão do SGA afim de propor novos objetivos e métodos que otimizem os resultados.

\subsection{Coleta e Análise de Dados}

A coleta de dados objetivou realizar um diagnóstico da situação da agroindústria no início da pesquisa. Para isso, considerou-se os impactos ao meio físico, biológico e socioeconômico das áreas de influência direta e indireta e a caracterização da cobertura vegetal local.

Incialmente, como meio de avaliação dos impactos ambientais ao meio físico e biológico, avaliou-se a situação da empresa acerca do licenciamento ambiental. Posteriormente, quantificou-se o consumo de água e de energia, bem como, o sistema de tratamento e destino de resíduos líquidos e sólidos. A avaliação dos impactos ambientais ao meio biótico também se deu pela verificação da manutenção de área verde e de reserva legal.

A qualificação e a quantificação dos resíduos tiveram como base, a atividade industrial inserida no período de 30 dias, correspondendo a um total de 2080 frangos abatidos.
Os impactos ambientais identificados como decorrentes das atividades operacionais foram transformados em objetivos, tais objetivos, devem ser priorizadas pela empresa. As ações identificadas foram organizadas em um SGA simplificado, que apresenta o objetivo das ações a serem desenvolvidas, as metas a serem alcançadas, as ações propostas para promover esse desenvolvimento e os prazos para o cumprimento.

\section{RESULTADOS}

\subsection{Diagnóstico Ambiental Preliminar das Áreas de Influência}

A delimitação das diferentes áreas de influência para o empreendimento, foi definida com base na atividade desenvolvida no local. Portanto, delimitou-se a área diretamente afetada, como sendo aquela onde o empreendimento está implantado e a área de influência direta, como sendo aquela área circunvizinha entendida como área do entorno ou como indireta.

A área destinada à implantação do empreendimento compreende $800 \mathrm{~m}^{2}$, sendo área útil de $228 \mathrm{~m}^{2}$, contendo vários pontos de influência ambiental, identificando-se um curso d'água que corta a propriedade da agroindústria e duas nascentes. O curso d'água origina-se no terreno vizinho e as nascentes originam-se no terreno do proprietário. Em uma das nascentes houve interferência para sua utilização, ou seja, foi feita a instalação do modelo caxambu e a canalização para utilização, que consistiu na inserção de um sistema de filtragem natural da água, preservando a qualidade e melhorando a disponibilidade.

\subsection{Características da Cobertura Vegetal da Área em Estudo}

A metodologia adotada para realizar a identificação das espécies de vegetais foi feita por comparação a partir de exemplares, com auxílio de literaturas especializadas e identificado as famílias pertencentes para oferecer maior fidelidade à análise dos dados coletados.

As espécies identificadas na área de influência da agroindústria e no entorno foram: Araucária angustifólia (Pinheiro); Ilex paraguarienses (Erva-mate); Lithraea brasiliensis (Aroera); Luehea devaricata (Açoita-cavalo); Machaerium paraguariense (Canela); Mimosa scabrella (Bracatinga); Morus nigra (Amoreira); Parapiptadenia rígida (Angico); Rollinia rugulosa (Araticum); Hovenia dulcis (UvaJapão); Syagrus romanzoffiana (Coqueiro - jerivá); Cárdia trichotoma (Louro); Cedrus (Cedro); Myrcianthes pungens (Guabiju); Ocotea pulchella (Canela do Brejo). O estrato herbáceo variou com espécies comuns regionais: Bacharis guadichaudiana (Vassoura); Pteridium aquilium (Samambaiadas-taperas); Baccharis sp. (Vassoura); Cortadelia sellowiana (Capim-navalha); Solanum erianthum (Fumo-bravo); Biden pilosa (Picão-preto); Baunilha candicans (Pata-de-vaca).

\subsection{Diagnóstico Atual da Empresa}

A agroindústria abatedora de aves possui $228 \mathrm{~m}^{2}$ de área útil para abate de 300 aves/dia e consome um volume de $8 \mathrm{~m}^{3} \mathrm{de}$ água por abate. Mantendo uma área de $36.000 \mathrm{~m}^{2}$ de reserva ambiental averbada, a água utilizada no abate é oriunda da nascente protegida pelo modelo caxambu.

A empresa possui um sistema de geração de energia 
renovável, proporcionado uma contribuição positiva à humanidade por ser uma energia limpa e ilimitada, sendo obtida por módulos fotovoltaicos que transformam a energia solar em energia elétrica. (FRANCO et al., 2018). O sistema fotovoltaico instalado permite produzir energia suficiente para manutenção das atividades, o excedente é armazenado pela concessionária totalizando $4.030 \mathrm{kwh} / \mathrm{mês}$.

Os resíduos líquidos gerados durante o abate são tratados em uma Estação de Tratamento de Efluentes (ETE). O principal objetivo do processo é a diminuição dos valores de Demanda Bioquímica de Oxigênio (DBO5,20) presentes nos resíduos líquidos, sendo representa pela quantidade de oxigênio necessária para oxidar a matéria orgânica presente na água através da decomposição microbiana aeróbia durante um período de 5 dias em uma temperatura de $20^{\circ} \mathrm{C}$. (ANA, 2019). O layout da ETE está apresentado no Figura 2.

\section{Figura 2 - Estação de Tratamento de Efluentes}

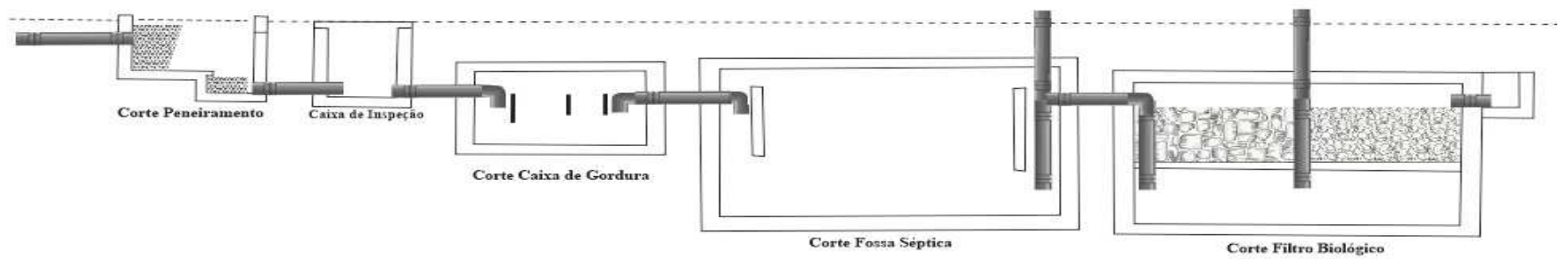

Fonte: Os autores (2020).

O processo da ETE baseia-se em uma sequência de processos físicos e biológicos, promovendo a separação e a transformação das matérias sólidas presentes no resíduo, deixando este em condições adequadas de disposição no meio ambiente por meio do sumidouro.

A validação do sistema de tratamento é realizada pela análise do efluente ao final do processo. O laboratório credenciado responsável avalia o tratamento de acordo com a Lei Estadual $\mathrm{n}^{\circ} 14.675 / 2009$, que estabelece os padrões de lançamento de efluentes líquidos em concordância com a resolução CONAMA n 430/11.

O Relatório Técnico de Monitoramento do Efluente confirma que a empresa atende as condicionantes ambientais da Autorização Ambiental do empreendimento, conforme solicitação de prestação de serviços ambientais de 06 de julho de 2017, ou seja, foram feitas análises dos efluentes bruto e tratado, comparando o resultado do sistema de tratamento e concluindo que apresenta a eficiência necessária que a resolução CONAMA $n^{\circ} 430 / 2011$, e a Lei Estadual $n^{\circ} 14.675 / 2009$ exigem, podendo ser lançado em corpos receptores sem causar danos ambientais ao meio aquático. Na Tabela 1, apresenta-se o resultado da análise presente no Relatório Técnico de Monitoramento de Efluente, comprovando o atendimento aos parâmetros de eficiência de remoção de poluentes.

Tabela 1 - Atendimento aos parâmetros de eficiência de remoção de poluentes.

\begin{tabular}{|c|c|c|c|c|}
\hline PARÂMETRO & BRUTO & TRATADO & $\begin{array}{c}\text { ATENDIMENTO A } \\
\text { VMP [1] [2] }\end{array}$ & EFICIÊNCIA (\%) \\
\hline \multicolumn{5}{|c|}{ Físico-Químico } \\
\hline DBO $5(\mathrm{mg} / \mathrm{L})$ & 772 & 47,34 & SIM & 93,86 \\
\hline Óleos e Graxas Totais $(\mathrm{mg} / \mathrm{L})$ & 265 & 6 & NÃO SE APLICA & 97,73 \\
\hline $\mathrm{pH}\left(\mathrm{pH}\right.$ a $\left.25^{\circ} \mathrm{C}\right)$ & 7 & 6,49 & SIM & - \\
\hline Sólidos Sedimentáveis $(\mathrm{ml} / \mathrm{L})$ & 4 & $<0,5$ & SIM & 87,5 \\
\hline \multicolumn{5}{|c|}{ Orgânicos } \\
\hline DQO (mg/L) & $2.590,00$ & 130,78 & NÃO SE APLICA & 94,95 \\
\hline \multicolumn{5}{|c|}{ [1] Resolução CONAMA n 430, de 13 de maio de 2011 - Seção I e II } \\
\hline \multicolumn{5}{|c|}{ [2] Lei 14.675 , de 13 de abril de 2009- Código Ambiental de Santa Catarina } \\
\hline
\end{tabular}

Fonte: Laboratório Terranálises (2018)

A agroindústria possui Autorização Ambiental e Licença ambiental de operação (LO) emitido pela FATMA, em 2016, com validade de 48 meses, sendo conferido pelo inciso I do artigo $7^{\circ}$ da Lei estadual $n^{\circ} 14.675$ de 2009, com base no processo de licenciamento ambiental e parecer técnico. As condições específicas do licenciamento, é realizar a devida manutenção aos controles ambientais, de maneira a manter sua eficiência e utilizar o Programa de Gerenciamento de Resíduos Sólidos (PGRS) e o programa de monitoramento de efluentes líquidos.

A qualificação e a quantificação dos resíduos gerados durante o processo de abate das aves, foi realizado seguindo o fluxo produtivo durante 08 abates, no período de 30 dias, são apresentados na Tabela 2.

O abate divide-se em duas áreas, área suja (AS) e a área limpa (AL). A AS compreende os processos de insensibilização, escaldagem, depenagem e primeira lavagem das aves. Já a AL compreende os processos de evisceração, segunda lavagem, pré resfriamento em chiller, gotejamento, corte das aves, embalagens e congelamento. Após a finalização do processo de industrialização, inicia-se a lavagem das AL e AS, juntamente com todos os equipamentos utilizados no processo. O total de água consumida na AS e AL é de $0,6 \mathrm{~m}^{3}$ e $1,4 \mathrm{~m}^{3}$ respectivamente.

$\mathrm{Na}$ agroindústria, os resíduos orgânicos do abate 
(vísceras, penas, sangue e frangos condenados ante mortem (que antecede o abate)) de acordo com o CONSEMA $n^{\circ}$ 99, de 5 de maio de 2017 tem um potencial poluidor geral Médio (M), sendo cadastrada como uma empresa de pequeno porte com capacidade de $200 \leq$ CmedA $\leq 15.000$ (Relatório Ambiental Prévio). Os resíduos orgânicos possuem uma destinação correta, estando conservado em refrigeração adequada até o recolhimento, além disso a destinação dos resíduos orgânicos e a sua classificação de não perigoso, apresenta um julgamento do solo, da água e do ar, em acordo à Lei $n^{\circ} 6.938 / 81$ e a NBR 10004. Os resíduos sólidos inorgânicos, que são os plásticos, produto reciclável, não possuem destino apropriado, possuindo essa falha com os resíduos.

Tabela 2 - Qualificação e quantificação dos resíduos gerados no processo produtivo. Fonte: $O$ autor (2020).

\begin{tabular}{|c|c|c|c|}
\hline Etapa & Resíduo & $\begin{array}{c}\text { Líquido } \\
\text { (litros) }\end{array}$ & $\begin{array}{c}\text { Sólido } \\
\text { (kg) }\end{array}$ \\
\hline Insensibilização & Água & 880 & 0 \\
\hline Sangria & Sague & 0 & 173 \\
\hline Escaldagem & Água & 2273 & 0 \\
\hline Depenagem & Água & 4477 & 0 \\
\hline $\begin{array}{c}\text { Depenagem } \\
\text { Primeira lavagem das } \\
\text { aves }\end{array}$ & Ṕna & 0 & 186 \\
\hline Avisceração & Água & 3513 & 0 \\
\hline Evisceração & Vísceras & 0 & 895 \\
\hline Segunda lavagem das & Água & 17811 & 0 \\
\hline aves & Água & 14400 & 0 \\
\hline Pré resfriamento & Água & 4800 & 0 \\
\hline Lavagem da AS & Água & 11200 & 0 \\
\hline Lavagem da AL & Plástico & 0 & 16 \\
\hline Embalagem & Matéria & 0 & 41 \\
\hline Caixa de gordura & orgânica & 0 & 0 \\
\hline Total & & $\mathbf{6 4 5 4 7}$ & $\mathbf{1 3 1 1}$ \\
\hline
\end{tabular}

Fonte: Os autores (2020).

\subsection{Coleta e Análise de Dados}

O Figura 3 apresenta a proposta de SGA de acordo com o método PDCA, onde analisou-se todos os impactos ambientais com base no diagnóstico inicial, bem como a sequência de atividades propostas à execução do PDCA.
Figura 3 - Sistema de Gestão Ambiental.

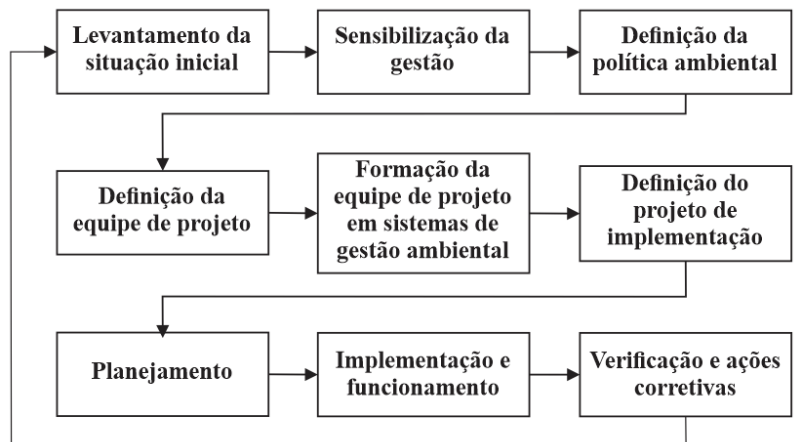

Fonte: Os autores (2020).

Com o diagnóstico inicial finalizado, efetuou-se a análise do tratamento do resíduo líquido e analisou-se a destinação dos resíduos sólidos, além de quantificar a água utilizada na industrialização. Assim sendo, o próximo passo foi apresentar para a gestão da organização as vantagens da implementação do SGA, que possibilita uma melhoria da imagem da agroindústria, aumento da competitividade, redução dos custos e entre outras vantagens que podem resultar. Conforme a realidade da agroindústria, identificada no diagnóstico inicial, definiu-se a política ambiental e a formação da equipe do projeto, seguindo as competências individuais de cada colaborador. $\mathrm{O}$ planejamento é o próximo passo, onde foram apresentados os impactos ambientais e também os requisitos legais.

No planejamento a agroindústria estabeleceu os objetivos, as competências e as responsabilidades individuais, apresentado os resultados mensalmente em reuniões aos gestores da organização a fim de demonstrar o comprometimento com o SGA. Os objetivos estabelecidos para o projeto compreenderam a avaliação e minimização dos impactos ambientais gerados. Para a implementação e funcionamento do planejamento, definiram-se recursos, atribuições, responsabilidades e autoridade de todos os colaboradores, tudo através de formação, sensibilização e competência. O último passo do PDCA foi a verificação e ações corretivas, onde efetuou-se uma análise crítica da implementação do SGA identificando desvios e corrigindo-os.

O diagnóstico inicial realizado na agroindústria apontou a presença de dois grandes impactos que não são minimizados com os sistemas de tratamento já existentes na empresa: o elevado consumo de água e a geração de resíduos sólidos não biodegradáveis-plástico. Diante disto, tomou-se como objetivo a definição do projeto de implementação de melhoria quanto ao consumo de água e geração de resíduos, que foi realizada com base no diagnóstico inicial dos impactos ambientais realizados, estando apresentados no Tabela 3.

Tabela 3 - Projeto de implementação de minimização de impactos ambientais.

\begin{tabular}{|c|c|c|c|c|}
\hline \multicolumn{2}{|c|}{ Impactos Ambientais } & \multicolumn{2}{c|}{ Objetões } & \multicolumn{2}{c|}{ Verificações } & Ações corretivas \\
$\begin{array}{c}\text { Resíduos sólidos não } \\
\text { biodegradáveis (plástico) }\end{array}$ & Destinação correta & $\begin{array}{c}\text { Aplicar a logística } \\
\text { reversa }\end{array}$ & $\begin{array}{c}\text { Através de documentos de } \\
\text { transportes assinados na retirada } \\
\text { dos resíduos }\end{array}$ & Aplicar a Lei no 12.305 \\
\hline Elevado consumo de água & Redução do consumo & $\begin{array}{c}\text { Investir em torneiras } \\
\text { com arejadores e } \\
\text { treinamentos }\end{array}$ & $\begin{array}{c}\text { Analisar o consumo de água nos } \\
\text { abates }\end{array}$ & $\begin{array}{c}\text { Manutenção preventiva } \\
\text { das torneiras }\end{array}$ \\
\hline
\end{tabular}

Fonte: Os autores (2020). 
A melhoria oportuna, quanto aos resíduos sólidos de embalagens plásticas e embalagens de produtos em geral, consistiu no destino correto destes para as cooperativas de catadores de materiais recicláveis efetuando a logística reversa. A logística reversa é estabelecida pela Lei $\mathrm{n}^{\circ} 12.305$, de 2 de agosto de 2010, e seu regulamento, Decreto $\mathrm{n}^{\circ} 7.404$ de 23 de dezembro de 2010, que destacam o compartilhamento da responsabilidade do ciclo de vida dos resíduos (BRASIL, 2010).

O elevado consumo de água pôde ser minimizado investindo em equipamentos, como torneiras com arejadores na limpeza das aves. As torneiras com arejadores, de acordo com o
Rezende (2019) misturam ar e água, passando a sensação de pressão e tendo uma redução no consumo de água de aproximadamente $75 \%$. Para o processo de lavagem das aves e evisceração, processos onde mais se utiliza água, foi realizado treinamentos com os colaboradores que atuam nestes processos, para utilização da melhor maneira possível a água. Essa melhoria teve uma redução importante na utilização de água, representando inicialmente $37 \%$ de redução no consumo, estando presente o quantitativo no Figura 4, onde possui o comparativo de antes e depois da instalação das torneiras com arejadores e treinamento dos colaboradores.

Figura 4 -Consumo de água (litros) em cada etapa do processo.

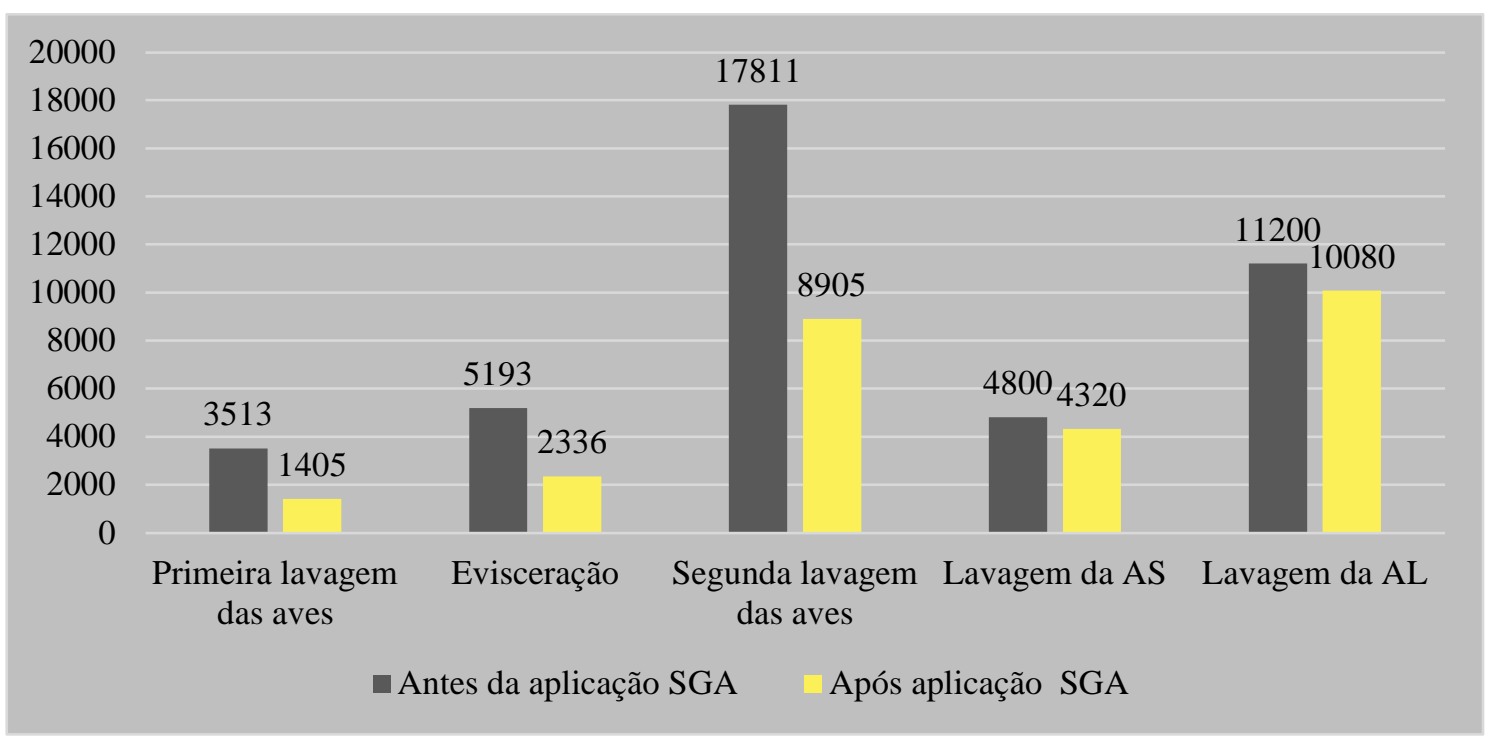

Fonte: Os autores (2020).

\section{CONSIDERAÇÕES FINAIS}

Este estudo buscou proporcionar a visão da aplicação do SGA em uma agroindústria de aves, apresentando os resultados obtidos na implantação do sistema, mostrando ser uma ferramenta tecnicamente viável, priorizando os principais problemas ambientais presentes. Analisando o resultado da coleta de dados, foi possível identificar a situação atual da agroindústria relacionado a produção de resíduos e na utilização de água.

De um modo geral, analisou todo o processo de produção da agroindústria e foi identificado todos os pontos que deveriam ser melhorados para reduzir os impactos ambientais, abrangendo os resíduos líquidos e sólidos. No resíduo líquido, foi quantificado o consumo de água, com isso, foram efetuados investimentos de equipamentos e treinamento para os colaboradores para redução de consumo de água, além disso, foi analisado o ETE, apresentando uma eficiência de $93 \%$ no DBO5,20, Relatório Técnico de Monitoramento do Efluente.

Analisando os resíduos sólidos, foi quantificado e analisado o recolhimento dos resíduos sólidos biodegradáveis, sendo efetuado por uma empresa credenciada de reaproveitamento, estando de acordo com a Lei analisada. Os resíduos sólidos não biodegradáveis, foram corretamente destinados para a associações cooperativas de catadores de materiais recicláveis e começou a efetuar a política reversa.

A elaboração do SGA limitou-se a parte da industrialização da agroindústria, devido à complexidade do assunto. Para uma melhoria contínua, sugere-se elaborar o SGA na parte produtiva das aves, ou seja, na produção de ração e na criação das aves nos aviários e integrar na industrialização, proporcionando um resultado mais expressivo.

\section{R E F E R Ê N C I A S}

ANA (Agência Nacional de Águas), Indicadores de qualidade: índice de qualidade das águas (IQA). Disponível em: $<$ http://pnqa.ana.gov.br/indicadores-indiceaguas.aspx\#_ftn4>. Acesso em: 03 out. 2019.

ALVES, E. A. C. O PDCA como ferramenta de gestão da rotina. In: CONGRESSO NACIONAL DE EXCELENCIA EM GESTÃO. Anais... 2015. Disponível em: <http://www.inovarse.org/sites/default/files/T_15_017 M_7.pdf>. Acesso em: 30 jun. 2019.

ASSOCIAÇC̃O BRASILEIRA DE PROTEINA ANIMAL 
- ABPA. Protocolo de bem-estar para frangos de corte. São Paulo, SP. 2016. Disponível em: <http://abpabr.com.br/storage/files/protocolo_de_bem-

estar_para_frangos_de_corte_2016.pdf>. Acesso em: 21 jun. 2019.

BARAUNA, D. et al. Sistema de Gestão Ambiental (SGA): uma aplicação na reciclagem de papel com fibra de bananeira.

Revista Brasileira de Gestão e Desenvolvimento Regional, Taubaté, v. 7, n. 2, p. 90-121, mai./ago. 2011. Disponível em: <https://www.rbgdr.net/revista/index.php/rbgdr/article/v iew/425/242>. Acesso em: 19 jun. 2019.

BOFF, L. Sustentabilidade: O que é - O que não é. Petrópolis, RJ: Vozes, 2017. Disponível em: <https://books.google.com.br/books?hl=pt-

BR\&lr=\&id=px46DwAAQBAJ\&oi=fnd\&pg=PT2\&dq= sustentabilidade\&ots=bDsoow $8 \mathrm{cxb} \& \operatorname{sig}=\mathrm{KSq}$ tmO9W5 b74Uj5j4NJiHVJwJgY\#v=onepage \&q=sustentabilidade $\& \mathrm{f}=$ false $>$. Acesso em: 21 jun. 2019.

BRASIL. DECRETO No 7.404, DE 23 DE DEZEMBRO DE 2010. Política Nacional de Resíduos Sólidos, Brasília, DF, ago, 2010. Disponível em: <http://www.planalto.gov.br/ccivil_03/_Ato20072010/2010/Decreto/D7404.htm>. Acesso em: 07 out. 2019.

BRASIL. LEI No 12.305, DE 2 DE AGOSTO DE 2010. Política Nacional de Resíduos Sólidos, Brasília, DF, ago, 2010. Disponível em: <http://www2.mma.gov.br/port/conama/legiabre.cfm?c odlegi=636>. Acesso em: 07 out. 2019.

BRASIL. RESOLUÇÃO CONAMA N 430, DE 13 DE MAIO DE 2011. Gestão do lançamento de efluentes em corpos de água receptores, Brasília, DF, maio, 2011. Disponível em:

<http://www2.mma.gov.br/port/conama/legiabre.cfm?c odlegi=646>. Acesso em: 21 jun. 2019.

CONSELHO ESTADUAL DO MEIO AMBIENTE. RESOLUÇÃO CONSEMA No 99. 2017. Disponível em: <http://www.pmf.sc.gov.br/arquivos/arquivos/pdf/2_CO NSEMA\%20_99_2017.pdf >. Acesso em: 31 jul. 2019.

DIAS, R. Gestão Ambiental: Responsabilidade Social e Sustentabilidade. 3. ed. São Paulo: atlas, 2017.

EMPRESA BRASILEIRA DE PESQUISA AGROPECUÁRIA - EMBRAPA. Agroindústria. Brasília, DF. 2018. Disponível em: <https://www.embrapa.br/grandescontribuicoes-para-a-agricultura-

brasileira/agroindustria>. Acesso em: 21 jun. 2019.

FOGLIATTI, M. C. et al. Sistema de Gestão Ambiental para Empresas. Rio Janeiro: Interciência, 2008.

FRANCO, R. A. P. et al. Estimação de Parâmetros de Modelo de Sistemas Fotovoltaicos utilizando Algoritmo de Levenberg-Marquardt Modificado, Tema, v. 19, n. 1, p. 79-92. 2018. Disponível em: <http://www.scielo.br/pdf/tema/v19n1/2179-8451-tema19-01-79.pdf >. Acesso em: 03 out. 2019.

LHAMBY, A. R.; SENNA, A. J. T.; CANES, S. E. A prática da gestão ambiental agroindustrial: um estudo de caso em uma agroindústria que produz energia elétrica a partir da casca do Arroz. IBEAS - Instituto Brasileiro de Estudos Ambientais, 2010.

MOURA, L. A. A. Qualidade e Gestão Ambiental: Sustentabilidade e ISO 14001. 6. ed. Belo Horizonte: Del Rey. 2011.
PEREIRA, T. R. Análise Global da Qualidade das Rodovias Estaduais e sua Inter-Relação com o Custo de Transporte Rodoviário no Estado De Santa Catarina. 2017. 46f. Trabalho de Conclusão de Curso - UNISUL, Tubarão, $2017 . \quad$ Disponível em: <http://www.riuni.unisul.br/handle/12345/3766>. Acesso em: 21 jun. 2019.

RAUPP, F.; SELIG, P. M.; SORIANO-SIERRA, E. J. Determinação de indicadores de desempenho ambiental para as indústrias sucroalcooleiras. Revista Gestão Industrial, Paraná, v. 11, n. 01, p. 47-68, 2015.

REZENDE, O. M.; Redutores de vazão proporcionam economia de água. Aecweb, 2019. Disponível em: <https://www.aecweb.com.br/cont/m/rev/redutores-devazao-proporcionam-economia-deagua_14778_10_19>. Acesso em: 07 out. 2019.

RIBEIRO, D. V.; MORELLI, M. R. Resíduos sólidos: problemas ou oportunidade? Rio de Janeiro: Interciência, 2009.

RODRIGUES, L. G. at al. Transações Entre os Agentes: Cooperativas, Agroindústria Aurolat e Distribuidores. RACE, Unoesc, v. 11, n. 1 Edição Especial Agronegócios, p. 151-178, jan./jun. 2012.

SANTA CATARINA. LEI No 14.675, DE 13 DE ABRIL DE 2009. Da política estadual do meio ambiente. Florianópolis, SC, abr, 2009. Disponível em: <http://leis.alesc.sc.gov.br/html/2009/14675_2009_lei.h tml>. Acesso em: 21 jun. 2019. 